\title{
A Chronic Implant to Record Electroretinogram, Visual Evoked Potentials and Oscillatory Potentials in Awake, Freely Moving Rats for Pharmacological Studies
}

\author{
Irene Guarino, ${ }^{1-2}$ Stefano Loizzo, ${ }^{1}$ Luisa Lopez, ${ }^{1-3}$ Antonello Fadda ${ }^{1}$ and Alberto Loizzo ${ }^{1}$ \\ ${ }^{1}$ Istituto Superiore di Sanità, Via Regina Elena 299, 00161 Roma, Italy; ${ }^{2}$ University of \\ Salerno, Department of Pharmaceutical Sciences, via Ponte Don Melillo, 84084 Fisciano \\ (Salerno) Italy; ${ }^{3}$ Child Neurology Unit, University of Rome Tor Vergata, Center for \\ Developmental Disabilities, via Anagnina Nuova 13, 00046, Grottaferrata, Italy
}

SUMMARY

Electroretinogram (ERG), widely used to study the pharmacological effects of drugs in animal models (e.g., diabetic retinopathy), is usually recorded in anesthetized rats. We report here a novel simple method to obtain chronic implantation of electrodes for simultaneous recording at the retinal and cortical levels in freely moving, unanesthetized animals. We recorded cortical (VEPs) and retinal (ERGs) responses evoked by light (flash) stimuli in awake rats and compared the results in the same rats anesthetized with urethane $(0.6$ $\mathrm{mg} / \mathrm{kg}$ ) before and after the monocular administration of scopolamine methyl bromide (1\% solution). We also compared the retinal responses with those derived from a classic acute corneal electrode. Anesthesia induced consistent changes of several VEP and ERG parameters like an increase of both latency and amplitude. In particular, the analysis of the variation of latency, amplitude, and spectral content of rapid oscillatory potentials could be important for a functional evaluation of the visual system in unanes thetized versus anesthetized animals.

Reprint requests to: Alberto Loizzo, Istituto Superiore di Sanità, Viale Regina Elena, 299, 00161, Roma-Italy. e-mail alberto.loizzo@iss.it

\section{KEYWORDS}

urethane, scopolamine, VEPs, ERGs, OPs

\section{INTRODUCTION}

Electroretinograms (ERGs), visual evoked potentials (VEPs), and oscillatory potentials (OPs), neurophysiologic methods that yield reproducible results in routine clinical practice, provide an objective functional measure of the visual pathways and related neural systems. These methods have been studied in large groups of normal subjects and in patients having a wide variety of neurological, endocrine and dysmetabolic diseases. Visual evoked potentials and ERGs are used for diagnostic applications in the presence of dysfunction in retinal layers and/or in the occipital cortex (Parisi, 2001). Such techniques can also provide a further therapeutic approach through the possibility of monitoring neurophysiologic changes related to diseases, to the alteration in the number or concentration of neurotransmitters or drugs, or to other situations that modulate the neuronal response to external/ internal stimulation.

Instead, OPs reflect short-term synchronization of neuronal electrical activity. Oscillations around the gamma range $(40$ to $100 \mathrm{~Hz}$ ) reportedly play a role in attention-related mechanisms and synaptic 
plasticity in cortical structures because they promote coherence and possible 'binding' of local and neuronal activity (Adjamian, 2004; Babiloni, 2004; Tallon-Baudry, 2003). Animal studies have been performed to confirm these hypotheses, in which the efficacy of various pharmacological agents or the differential impact of different behavioral states can be tested thoroughly (Van der Linden, 1999, Loizzo, 1998).

Although several studies have been published on VEPs, very few experiments have been carried out to study ERG parameters in awake rats (SzaboSalfay, 2001; Galambos, 1994). In fact, such studies generally refer to restrained (Boyes, 1983) or anesthetized animals, with acute electrode implants (Schaeppi, 1988; Shaw, 1998), but anesthesia is known to affect electrophysiological responses (Dyer, 1994; Rigdon, 1988; Hetzler, 1989; Porciatti, 1999). Therefore, here we describe a new method to analyze the visual system of freely moving, unanesthetized rats that provides a model for simultaneously recording potentials at both retinal and cortical levels. This technique has been used in mice with optimal compliance (Lopez, 2002; Loizzo, 2002). We performed a comparison of retinal responses derived from this new method with those obtained from a 'classic' acute implant of electrodes, which is usually performed in anesthetized animals, using surface corneal electrodes. Furthermore, we verified the effects of a cholinergic antagonist using quaternary scopolamine because the structure of the molecule prevents crossing through blood-brain barrier, thus behaving as typical mydriatic agents used in patients and experimental rats.

\section{EXPERIMENTAL}

\subsection{Animals}

Sprague Dawley rats (Charles River Italy, Calco, Italy) $(\mathrm{n}=8)$ weighing $250 \mathrm{~g}$ each were housed in a transparent plastic cage under standard animal conditions with free access to food and water, a $12 \mathrm{hrs}$ light/dark cycle, and an ambient temperature of $21^{\circ} \mathrm{C}$. The animal care and use followed the directives of the Council of the European Communities. The Bioethical Committee of the Italian National Institute of Health approved the experimental protocol.

\subsection{Surgery}

Under xylazine (Rompun, Bayer AG, Leverkusen-Germania, $20 \mathrm{mg} / \mathrm{kg}$ i.p.) and ketamine (Ketavet 100, Gellini Farmaceutici Spa, Peschira Borromea-MI, $32 \mathrm{mg} / \mathrm{kg}$ i.p.) and locally injected lidocaine (Lidocaina 2\%, Azienda Terapeutica Italiana A.T.I. srl, Ozzano Emilia-BO, $0.1 \mathrm{ml} \mathrm{s.c.)}$ anesthesia, the animals were chronically implanted, the position of electrodes being determined with reference to the sagittal suture and bregma. For each animal, four L-shaped monopolar epidural stainless-steel electrodes $(0.8 \mathrm{~mm}$ diam. $/ 15 \mathrm{~mm}$ length) were implanted on sensorimotor cortex for VEPs recording: left and right posterior $(5 \mathrm{~mm}$ from the bregma and $4 \mathrm{~mm}$ lateral to the sagittal suture bilaterally), right anterior ( $4 \mathrm{~mm}$ from the bregma and $2 \mathrm{~mm}$ from the sagittal suture). To assure stability to the dental cement implant on the skull, we positioned a fourth electrode symmetrical to the active one (left posterior, $1.5 \mathrm{~mm}$ caudal to bregma). This electrode was not connected. For flash ERGs recording two teflon coated tungsten electrodes $(0.2 \mathrm{~mm}$ diameter $)$, covered with an anallergic and insulating varnish, except for the tip $(0.5 \mathrm{~mm})$, were applied: one was used as reference and was inserted subcutaneously over the nasal bone (1.5 $\mathrm{cm}$ long), and one behind the ocular globe ( $7 \mathrm{~mm}$ long).

The position of ERG electrodes leaves the retina just in the middle. The "active" electrode was applied as to obtain a physical contact between the electrode tip and the eye's posterior tunica, and is placed after drilling the left anterior 


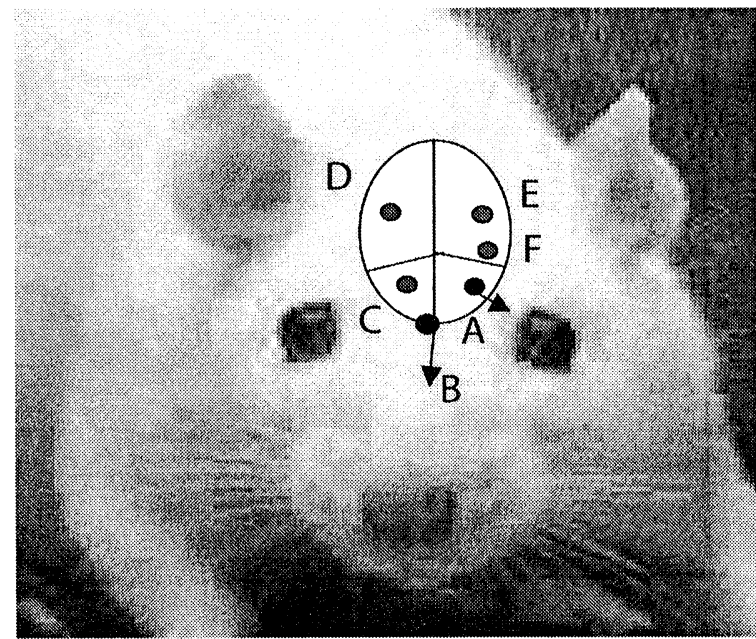

Fig. 1 A. ERG active electrode; B. ERG reference electrode; C. (D+) cortical electrode; D. (D-) cortical electrode; E. Ground cortical electrode. F. Support electrode, used only to enforce the electrode structure embedded in dental cement to the skull.

part of the skull ( $3 \mathrm{~mm}$ from the bregma and $2 \mathrm{~mm}$ from the sagittal suture). The drill (always held in the same hole) was inclined to leave of 35 degrees on the frontal plane and of 35 degrees on the sagittal plane to perforate the orbital bone behind the left eye. The recording electrode was inserted for $\sim 7$ $\mathrm{mm}$, so that the bare tip was in contact with the posterior part of the eye. We could control the position by gently pushing the electrode to induce a reversible extroflession of the eye. The implant was fixed with dental cement. During the surgery, a heated table maintained the body temperature at 37 ${ }^{\circ} \mathrm{C}$. A recovery period of 1 week was allowed before the ERG and EEG recordings.

\subsection{Stimuli}

A Grass Instrument PS 22 photic stimulator model supplied the flash stimulation. During the recording, 90 successive light flashes (stimulus rate:
1 flash per second, duration: $10 \mu \mathrm{s}$ ) were presented. Two intensities of stimulation, corresponding to $236.4 \mathrm{mcd} / \mathrm{m}^{2} *_{\mathrm{s}}$ and $945.6 \mathrm{mcd} / \mathrm{m}^{2} *_{\mathrm{s}}$ respectively, were used. The stimulus intensity range was chosen according to the results obtained in preliminary sessions published elsewhere (Lopez, 2002)

\subsection{Experimental protocol}

The recording sessions, each lasting $120 \mathrm{~min}$, took place at the same time each morning to avoid interferences due to circadian rhythm. Each rat was recorded alone while housed in a cage with mirrored walls, with the ceiling corresponding to the flash stimulator positioned outside the soundproof cage to avoid acoustic interferences. First, we recorded VEP and ERG in the awake, freely moving rat. Then the same animal was anesthetized with urethane (Sigma Chemical Co, Germany; 0.6 $\mathrm{mg} / \mathrm{kg}$ ) and VEP and ERG were recorded in both conditions, i.e., through the chronic and the acute implants. The latter consisted of a DTL electrode (Bayer, 2001) positioned in the conjuntival sac and recorded against a reference electrode inserted subcutaneously over the nasal bone. The recording procedure was repeated on the anesthetized animal, after placing $50 \mu \mathrm{l}$ of scopolamine (scopolamine methyl bromide, $1 \%$ solution, Sigma Chemical Co, Germany) on the left eye where the ERG electrodes were positioned.

The EEG and ERG signals were amplified through a DC powered preamplifier, with a gain of $1000 \mathrm{X}$ and an analogic filter at $1 \mathrm{~Hz}$ highpass (HP) and a $500 \mathrm{~Hz}$ lowpass (LP) $6 \mathrm{~dB} /$ octave. The acquisition was performed at $2 \mathrm{kHz}$ sampling rate. An InstruNet A/D 16 bit conversion board delivered the signals to the acquisition system (Superscope- GW Instruments, Somerville, Massachusetts, USA) on a personal computer (Macintosh 8150 Power PC) customized and adapted by Analysa (Villafalletto CU, Italy). Brain and retinal activity and trigger were continuously acquired and saved as raw data to be analyzed off-line. The 
protocol of the experiment was the following: a stimulation frequency of $1 \mathrm{~Hz}$ was used for each stimulation intensity, with a $10 \mathrm{~min}$ interval between each intensity level. The animals were not scotopically adapted. Repetitions were performed when more than 3 movement artifacts were visible in the raw data. The amplitude and latency of the VEP and the ERG responses were measured after baseline normalization. The latency was calculated as the absolute value between stimulus onset and the peak of the first negative response, whereas amplitude was taken both as an absolute value of negative peak amplitude and as peak-to-peak value between the first negative peak and the following most prominent positive peak. Oscillatory potentials (OPs) were extracted through the application of a digital $50 \mathrm{~Hz}$ HP filter (linear phase FIR, $6 \mathrm{~dB} /$ octave) to the raw data (Lopez, 2002). The latency of the oscillation was measured in ms from the trigger to the response peak. The amplitude was calculated as the peak-to-peak value between the first negative and the first positive peaks.

\subsection{Statistical analysis}

The latencies and peak-to-peak amplitudes of the major peaks of the evoked responses and of the OPs were measured, and the differences between pre- and post-treatment were compared in the same animal. The differences in latency and peak-topeak amplitude were evaluated using Student's $t$ test for paired data. When comparing the retinal responses coming from chronic and acute implants, Student's $t$ test for the difference of the average was used.

\section{RESULTS}

Figures 2.1, 2.2, and 2.3 contain illustrations of different types of visual responses recorded in the rat. We analyzed only $\mathrm{P} 2$ and $\mathrm{OP}_{2}$ for VEPs and $\mathrm{b} 2$ and $\mathrm{O}_{2}$ peaks for ERGs because it has been

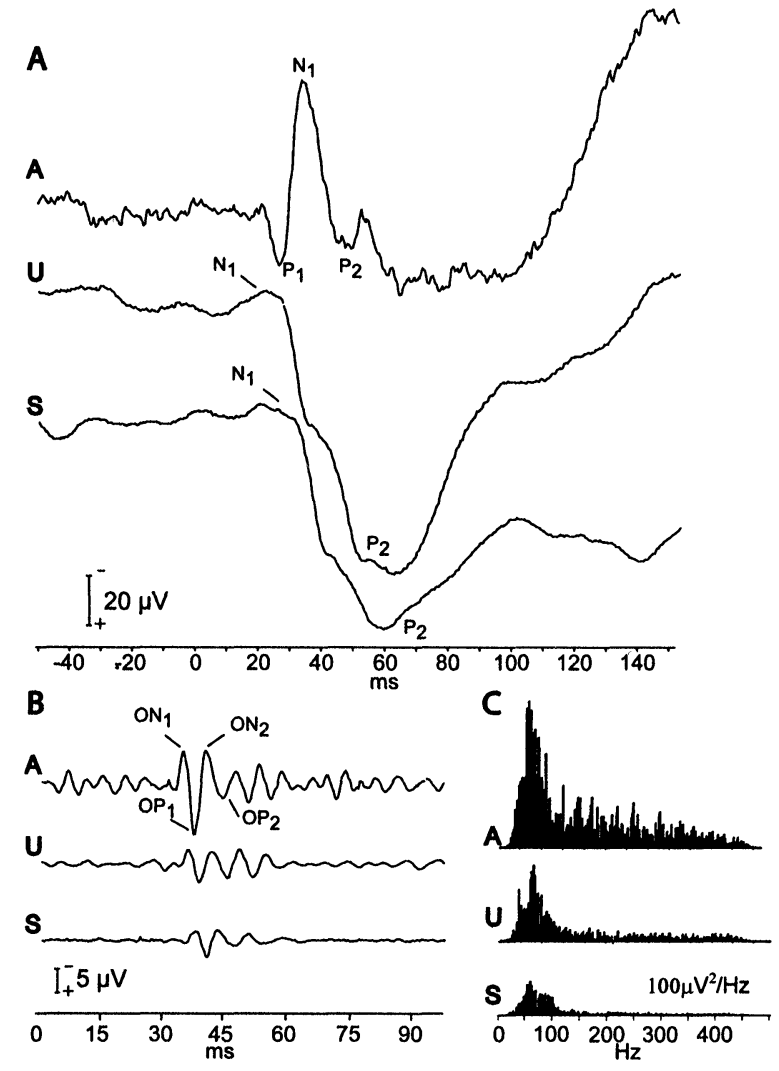

Fig. 2.1 A. Example of VEP in three different conditions: in awake (A), anaesthetized (U), and treated with scopolamine (S). Positive and negative peaks labeled as N1, $\mathrm{P} 2$, and N2 characterized baseline awake VEPs. B. Superimposed on peaks, a train of higher frequency positive and negative oscillatory potentials is labeled as $\mathrm{ON}_{1}, \mathrm{ON}_{2}$, and $\mathrm{OP}_{1}, \mathrm{OP}_{2}$, respectively C. Power spectrum of cortical oscillatory potentials shown in $\mathrm{B}$.

already shown that after anesthesia with urethane, the cortical VEPs show a change in morphology because of the disappearance of some negative peaks (Dyer, 1994). 


\subsection{VEP parameters before and after urethane and scopolamine}

In awake rats, $\mathrm{P} 2$ appeared at a mean latency of $46.5 \pm 1.8$ (SEM) ms and an amplitude of 24.2 $\pm 6.3 \mu \mathrm{V}$ at the lower intensity of stimulation and at a latency of $46.2 \pm 2.1 \mathrm{~ms}$ and an amplitude of $30.7 \pm 5.9 \mu \mathrm{V}$ at the higher intensity of stimulation.
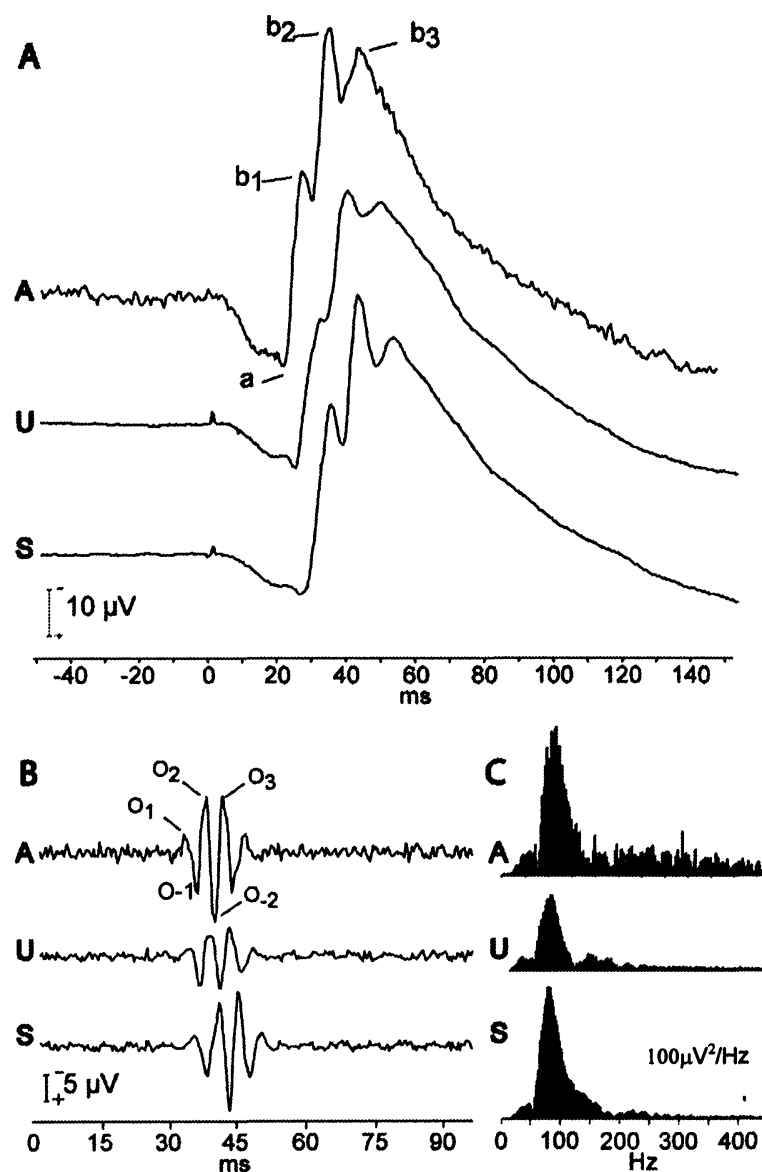

Fig. 2.2 A. Example of ERG recorded in rat in three different conditions: awake, anesthetized, and treated with scopolamine rat. The ERG waveform consists of an initial negative a- wave followed by the slow- high amplitude b-waves (identified as b1, b2, and b3). B. Superimposed on this potential there is a train of high positive and negative frequencies $\left(\mathrm{O}, \mathrm{O}_{2}, \mathrm{O}_{3}\right.$, and $\mathrm{O}_{-1}$ and $\mathrm{O}_{-2}$ respectively). C. Power spectrum of retinal oscillatory potentials shown in B.
After anesthesia it showed a consistent increase of latency $(62.9 \pm 2.3 \mathrm{~ms}$ and $58.8 \pm 1.7 \mathrm{~ms}$ at the lower and higher intensities of stimulation, in both cases $\mathrm{P}<0.01)$ (Fig. 3) and amplitude (66.2 $\pm 11.2 \mu \mathrm{V}$ and $88.7 \pm 11.9 \mu \mathrm{V}$ respectively, $\mathrm{P}<0.01$ ) (Fig. 4). The same trend of latency was observed after treatment with scopolamine methyl bromide (68.3 \pm $3.6 \mathrm{~ms} \mathrm{P}<0.05$ at lower and $61.3 \pm 2.7 \mathrm{~ms} \mathrm{P}<0.05$ at higher intensity of stimulation) (Fig. 3). The amplitude was lower then after anesthesia; this decrement was significant only at the higher intensity (88.7 \pm $11.9 \mu \mathrm{V} v s 44.4 \pm 13.2 \mu \mathrm{V}, \mathrm{P}<0.01$ ) (Fig. 4).

The peak $\mathrm{OP}_{2}$ showed a latency range between 38 and $43 \mathrm{~ms}$ at stronger intensity of stimulation in awake animals. Latency to intensity relationship curves displayed a very similar trend to VEPs, but amplitude decreased after anesthesia with urethane, especially at the lower intensity $(8.1 \pm 0.9 \mu \mathrm{V} v s$ $2.1 \pm 0.2 \mu \mathrm{V}, \mathrm{P}<0.01)$. The latency of $\mathrm{OP}_{2}$ increased after scopolamine $(55.7 \pm 0.7 \mathrm{~ms} v s 63.6$ $\pm 2.0 \mathrm{~ms}$ and $53.1 \pm 1.9 \mathrm{~ms} v s 59.3 \pm 2.9 \mathrm{~ms}$ at both intensities considered, $\mathrm{P}<0.05$ ) (Fig. 3), while amplitude decreased $(2.1 \pm 0.2 \mu \mathrm{V} v s 1.3 \pm 0.2 \mu \mathrm{V}$ and $2.6 \pm 0.5 \mu \mathrm{V}$ vs $1.3 \pm 0.2 \mu \mathrm{V} ; \mathrm{P}<0.05$ ) (Fig. 4).

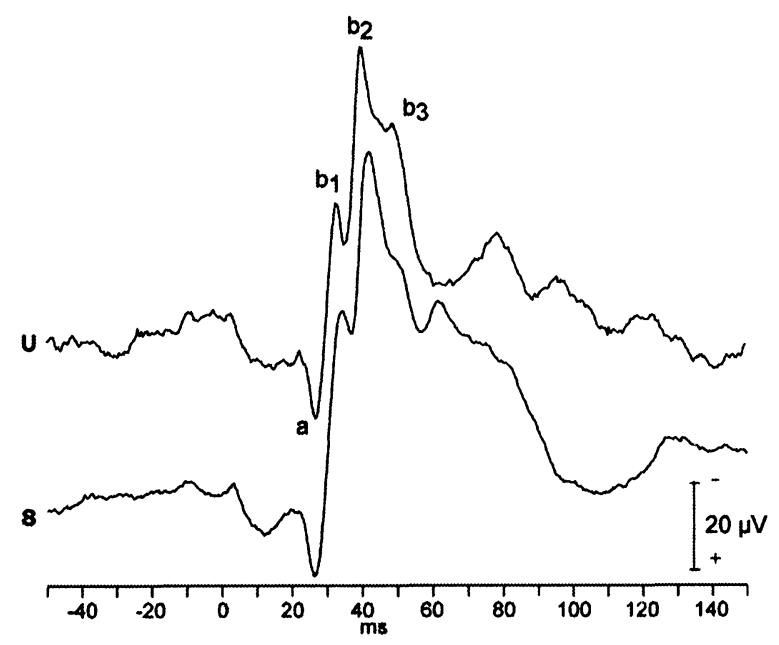

Fig. 2.3 Example of ERG recorded using the DTL acute electrode after both urethane and scopolamine 


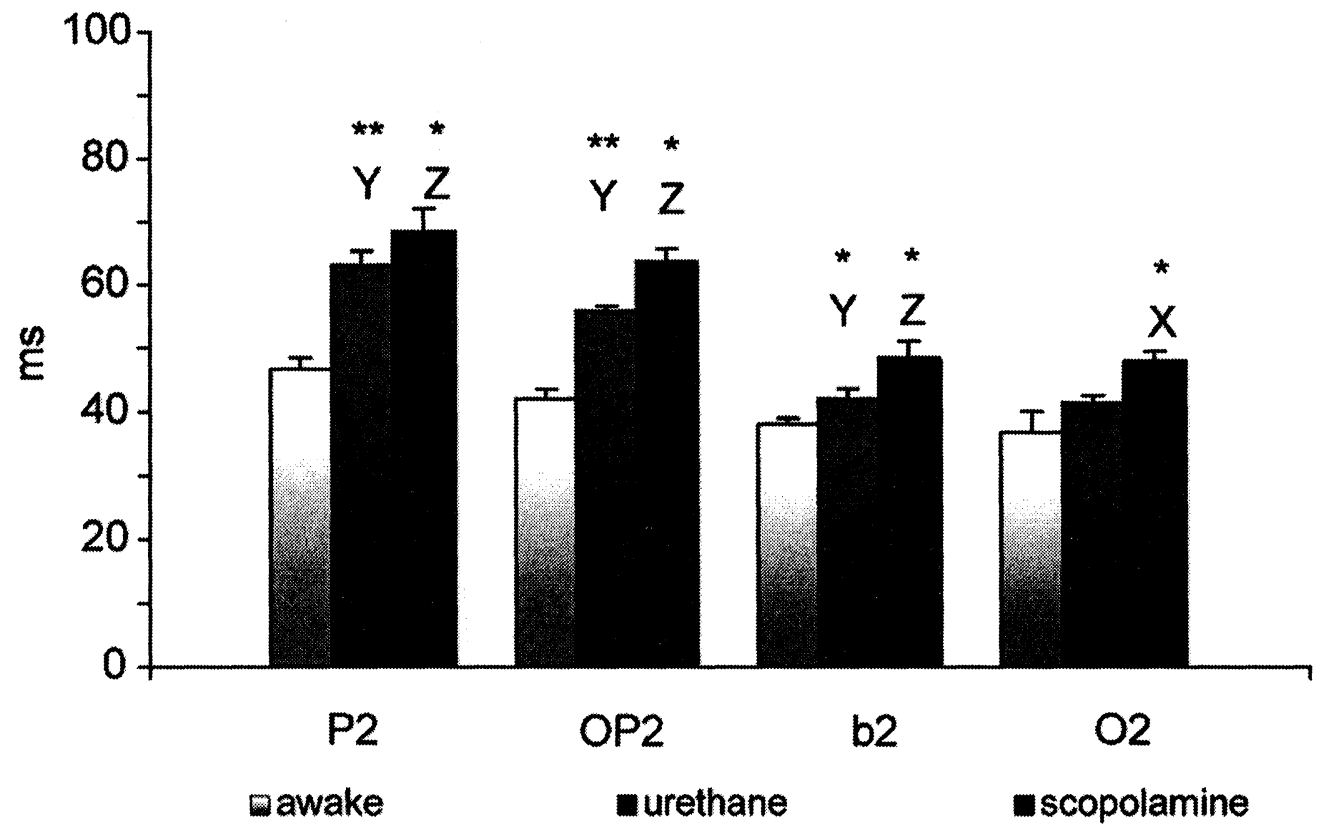

Fig. 3 Latency mean of the different peaks (P2, OP2, b2 and O2) evaluated in awake rat and after treatment with urethane and scopolamine. Data are elicited by the lower intensities of luminous stimulation $\left(236.4 \mathrm{mcd} / \mathrm{m}^{2 *} \mathrm{~s}\right)$. Symbols indicate: ${ }^{*}=$ $\mathrm{P}<0.05 ; * *=\mathrm{P}<0.01 ; \mathrm{Y}=$ awake $v s$ urethane; $\mathrm{Z}=$ urethane $v$ s scopolamine; $\mathrm{X}=$ awake $v s$ scopolamine.
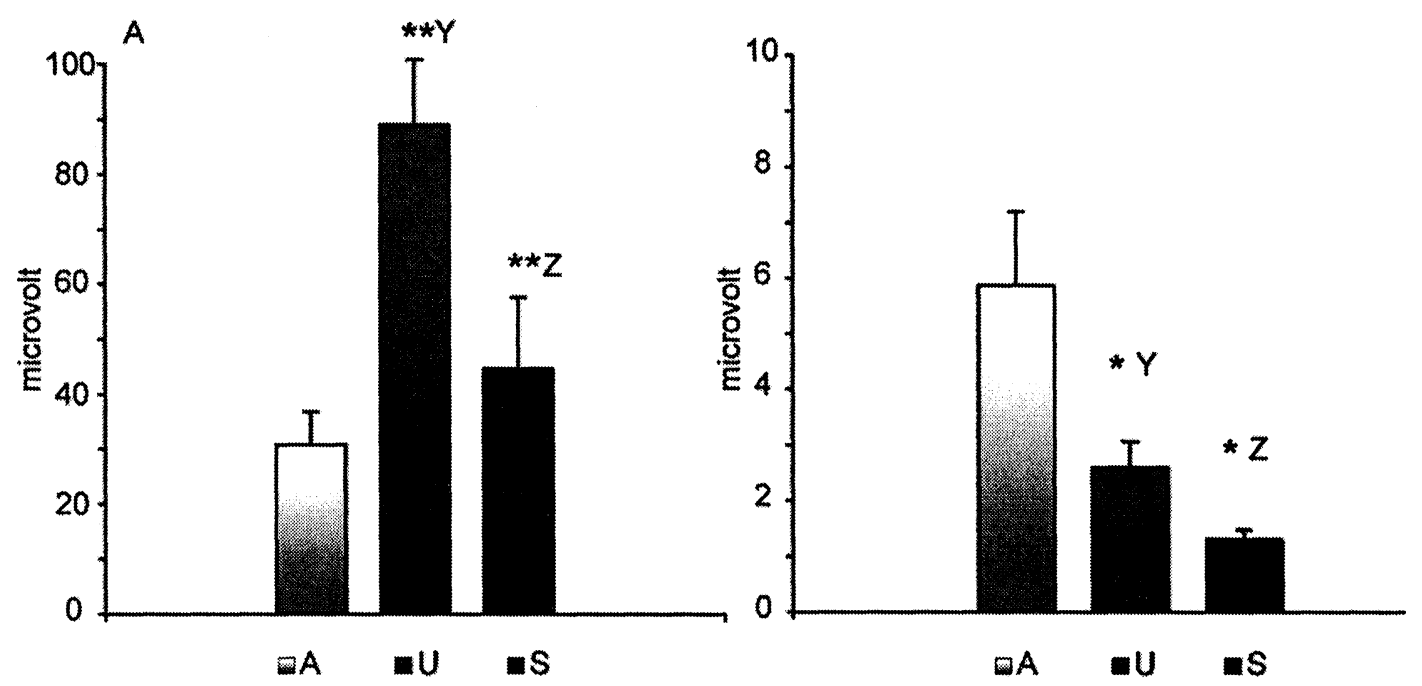

Fig. 4 Amplitude mean of $\mathrm{P} 2(\mathrm{~A})$ and $\mathrm{OP}_{2}(\mathrm{~B})$ peaks evaluated in awake (A) and after treatment with urethane (U) and scopolamine (S) rats. Data are elicited by the higher intensities of luminous stimulation $\left(945.6 \mathrm{~cd} / \mathrm{m}^{2 *}\right)$. Symbols indicate: $*=P<0.05 ;{ }^{* *}=\mathrm{P}<0.01$; $\mathrm{Y}=$ awake $v s$ urethane; $\mathrm{Z}=$ urethane $v s$ scopolamine; $\mathrm{X}=$ awake $v s$ scopolamine. 


\subsection{ERG parameters before and after urethane and scopolamine}

In awake animals, b2 showed a latency of 37.8 $\pm 1 \mathrm{~ms}$ at the lower intensity and a latency of $35.5 \pm$ $1.0 \mathrm{~ms}$ at the higher intensity of stimulation. After anesthesia we observed a significant $(P<0.05)$ increase of latency at lower intensity of stimulation $(41.9 \pm 1.6 \mathrm{~ms})$ and no significant variation of amplitude. The same trend was observed for the $\mathrm{O}_{2}$ wave (Fig. 3) especially after use of scopolamine methyl bromide ( $41.1 \pm 1.3 \mathrm{~ms}$. vs $47.8 \pm 1.6 \mathrm{~ms}$ at lower intensity; $\mathrm{P}<0.05$ ), these differences, however were not consistent after urethane. The b2 latency variations between electrical responses coming from chronic and acute electrodes were not observed, as expected. On the contrary, the amplitude of the same peak was different, especially at the higher intensity $(14.6 \pm 6.2 \mu \mathrm{V}$ vs $47.4 \pm 7.4 \mu \mathrm{V}$ respectively, $\mathrm{P}<0.01)$.

Comparing electrical responses coming from chronic and acute retinal electrodes a significant increase of response amplitude recorded from acute electrodes was also observed after using

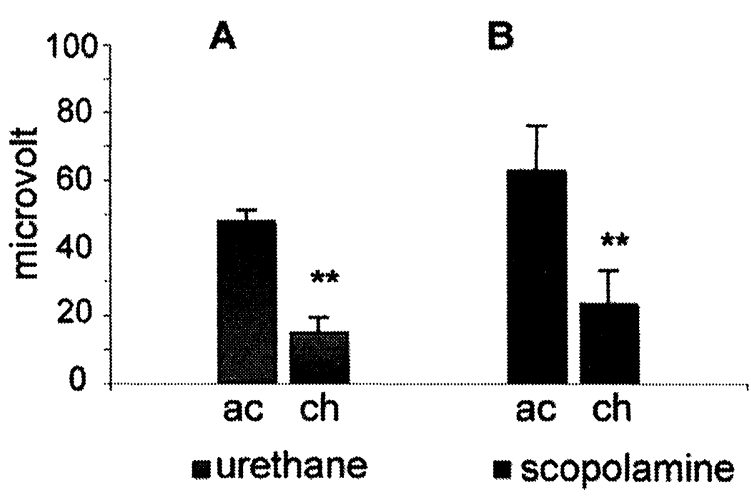

Fig. 5: Difference of b2 peak amplitude between chronic (ch) and acute (ac) implants after treatment with (A) urethane and (B) urethane + scopolamine ** indicates $\mathrm{P}<0.01$. scopolamine, especially at the higher intensity (28 $\pm 10 \mu \mathrm{V} v s 62.6 \pm 16 \mu \mathrm{V} ; \mathrm{P}<0.01$ ) (Fig 5).

Our experiment was based on the analysis of VEP, ERG, and OP (cortical and retinal) recorded under three different conditions: awake rats, anesthetized rats, and anesthetized rats topically treated with scopolamine methyl bromide. To obtain this experimental model on awake rats, it was first necessary to develop a method for a chronic retinal electrode implant similar to the one previously applied on mice (Lopez, 2002; Loizzo, 2002), on conscious dogs (Sato, 1982), and on monkeys or micropigs (Heynen, 1985; Rosolen, 1999). In particular, ERGs coming from the chronic implant were compared with those recorded from a classic acute one. In fact, the evoked responses from retina are usually recorded in anesthetized animals, but different anesthetics are known to affect the electrophysiological responses of the animal differently (Brown, 1984; Raitta, 1979; Vaegan, 1990). In our experimental conditions, urethane produced qualitative and quantitative alterations in the rat's VEPs. Qualitatively, the dominant effect was the abolition of the N1 peak, already observed by Dyer (1994); quantitatively, we observed a latency increase of the $\mathrm{P} 2, \mathrm{OP}_{2}, \mathrm{~b} 2$, and $\mathrm{O}_{2}$ peaks, a consistent amplitude increase of the P2 peak, and an amplitude decrease of the $\mathrm{OP}_{2}$ peak. The latency increase, a characteristic of many anesthetics, is due to a depression of conduction in the visual pathways. This effect is not unique to urethane. In general, substances that appear to increase GABAergic inhibition tend to increase the amplitude of the second positive peak evoked in cats by step increments in luminance, whereas substances that tend to decrease GABAergic inhibition tend to decrease the amplitude of this peak (Zemon, 1986).

The use of a digital $50 \mathrm{~Hz}$ HP filter was followed by a strong abatement of high frequencies in the spectrum of PEV and therefore of OPs (Fig. 4B). We cannot explain why urethane 
treatment is followed by an increase in P2 peak amplitude. One hypothesis is that the drug, which induces a diminution of high frequencies, induces as well a certain shift of frequency power toward lower frequencies.

When we compared the ERG coming from chronic and acute implants, we observed that $b 2$ of the acute implant showed a significant amplitude increase versus the responses coming from the chronic implant. The same trend was observed after local treatment with scopolamine methyl bromide. In the chronic implant, the electrode is positioned behind the ocular globe, and the insulating electric properties of sclera can interfere with the electric transmission of the signal, thus inducing a lower amplitude signal.

After using scopolamine methyl bromide, we also observed a further increase in the latency of the $\mathrm{P} 2, \mathrm{OP}_{2}, \mathrm{~b} 2$, and $\mathrm{O}_{2}$ peaks and a decrease in the amplitude of the $\mathrm{P} 2$ and $\mathrm{OP}_{2}$ peaks. In the literature, few and controversial data about scopolamine action on eye have been reported. Arakawa et al. (1997) found that in the anesthetized cat, scopolamine $(0.7 \mathrm{mg} / \mathrm{kg}$ i.v. $)$ increases the amplitude of the responses to ketamine and $1 \%$ halothane recorded from the primary visual cortex. Sannita et al. (1993, 1988), by contrast, showed that in conscious humans, scopolamine $(0.25,0.50$, and $0.75 \mathrm{mg} / \mathrm{kg}$ i.m.) reduces the amplitude of the late components of the flash-evoked potential without affecting latency. In addition, Harding (1994) investigated the action of a topical administration of $0.125 \%$ scopolamine applied monocularly and found no change in latency between the control and experimental and after administering scopolamine.

Our results suggest that this drug could alter not only the amplitude but also and especially the latency of electrical responses, so we suggest that antimuscarinic drugs applied as mydriatics during neurophysiologic experiments can induce variation in the retinal response, even if the drug hardly passes the blood brain barrier, as in the case of methyl bromide scopolamine. As our target was to compare retinal responses coming from chronic and acute implants in the same animals during the same experimental session, we did not perform a comparison between anesthetized and awake animals treated with scopolamine.

From the results of this study, we conclude that the use of the retinal chronic implant allows the recording of visual-evoked responses in awake animals, unrestrained, avoiding physiological changes coming from anesthesia, and possible interactions between the anesthetic and other drugs, which becomes essential when studying drugs acting on retinal pathophysiology. In conclusion, anesthesia in general induced a consistent increase of latency in both VEP and ERG, and an increase in the latency of the oscillatory potentials of VEP and ERG. Anesthesia also induced an increase in VEP amplitude, whereas no consistent differences were recorded for ERG. The oscillatory potentials of VEP were consistently reduced, whereas we could not gather enough data for ERG. An increase in the amplitude of potentials, however, accompanied by a reduction in the decrease of OPs amplitude induced by anesthesia, would indicate a shift of spectral content toward lower bands.

Oscillatory potentials latency and amplitude might be of particular importance in the evaluation of retinal damage and/or changes in neural plasticity induced by experimental (e.g. diabetes) conditions. Oscillatory potentials features can be also modulated during different behavioral states. Therefore, the use of chronic implants that allow recording the high-frequency spectral content of electric responses in awake, freely moving animals can be of help in the evaluation of retinal damage and of the protective effect of drugs (Yu, 1998). This kind of implant persists on site 30 to 45 days and can allow studies on neural/retinal conditions, evolution, and possible pharmacological treatment. 


\section{ACKNOWLEDGMENTS}

This work was in part supported by the Italian National Institute of Health Projects "Developmental Pharmacology" and "New Strategies for Prevention and Treatment of Cardiovascular Diseases" and in part by the "GIO.I.A FOUNDATION" ONLUS. The authors express deep gratitude to Ms. Carla Campanella for her excellent editorial work and to Mr. Stefano Fidanza and Mr. Adriano Urciuoli for the expert care of animals.

\section{REFERENCES}

Adjamian P, Holliday IE, Barnes GR, Hillebrand A, Hadjipapas A, Singh KD. 2004. Induced visual illusions and gamma oscillations in human primary visual cortex. Eur J Neurosci 20: 587-592.

Arakawa K, Tobimatsu S, Kato M, Kobayashi T. 1997. Different effects of cholinergic agents on responses recorded from the cat visual cortex and lateral geniculate nucleus dorsalis. Electroencephal Clin Neurophysiol 104: 375-380.

Babiloni C, Babiloni F, Carducci F, Cappa S, Cincotti F, Del Percio C, et al. 2004. Human cortical EEG rhythms during long-term episodic memory task. A high-resolution EEG study of the HERA model.. Neuroimage 21: 1576-1584.

Bayer AU, Cook P, Brodie SE, Maag KP, Mittag T. 2001. Evaluation of different recording parameters to establish a standard for flash electroretinography in rodents. Vision Res 41: 2173-2185.

Boyes WK, Dyer R. 1983. Pattern reversal visual evoked potentials in awake rats. Brain Res Bull 10: 817-823.

Brown CH, Green DG. 1983. Rod saturation in b-wave of the rat electroretinogram under two different anesthetics. Vision Res 24: 87-90.

Dyer RS, Rigdon GC. 1994. Urethane affects the rat visual system at subanaesthetic doses. Physiol Behav 41: 327-330.

Galambos R, Juhàsz G, Kèkesi AK, Nyitrai G. 1994. Natural sleep modifies the rat electroretinogram. Proc Natl Acad Sci 91: 5153-5157.

Green ES, Menz MD, LaVail MM, Flannery JG. 2000. Characterization of rhodopsin mis-sorting and constitutive activation in a transgenic rat model of retinitis pigmentosa. Invest Ophthalmol Vis Sci 41 : 1546-1553.

Harding GF, Daniels R, Panchal S, Drasdo N, Anderson SJ. 1994. Visual evoked potentials to flash and pattern reversal stimulation after administration of systemic or topical scopolamine. Doc Ophthalmol 86: 311-322.

Heynen H, Wachtmeister L, van Norren D. 1985. Origin of the oscillatory potentials in the primate retina. Vision Res 25: 1365-1373.

Hetzler BE, Melk AM. 1989. Effects of ketamine, naloxone and physostigmine on flash evoked potentials in rat superior colliculus. Pharmacol Biochem Behav 32: 511-518.

Lopez L, Brusa A, Fadda A, Loizzo S, Martinangeli A, Sannita WG, Loizzo, A. 2002. Modulation of flash stimulation intensity and frequency: effects on visual evoked potentials and oscillatory potentials recorded in awake, freely moving mice. Behav Brain Res 131: 105-114.

Loizzo A, Sannita WG, Lopez L, Conforto S, Narici L. 1998. A pharmacological approach to oscillatory potentials in mice. In: Hashimoto I, Kakigi, eds, Recent Advances in Human Neurophysiology. Amsterda, The Netherlands: Elsevier Science; 363-368.

Loizzo S, Lopez L, Pedrazzo G, Loizzo A. 2002. A neurophysiological approach to effects induced by accelerated particles on the central nervous system in mice. Ann Ist Super Sanità 38: 425-428.

Machida S, Kondo M, Jamison JA, Khan NW, Kononen LT, Sugawara $\mathrm{T}$ et al. 2000. P23H rhodopsin transgenic rat: Correlation of retinal function with histopathology. Invest Ophthalmol Vis Sci 41: 3200-3209.

Morrison JC, Nylander KB, Lauer AK Cepurna WO, Johnson E. 1998. Glaucoma drops control intraocular pressure and protect optic nerves in a rat model of glaucoma. Invest Ophthalmol Vis Sci 39: 526-531.

Parisi V, Uccioli L. 2001. Visual electrophysiological responses in persons with type 1 diabetes. Diabetes Metab Res Rev 17: 12-18.

Porciatti V, Pizzorusso T, Maffei L. 1999. The visual physiology of the wild type mouse determined with pattern VEPs. Vis Res 39: 3071-3081.

Raitta C, Karhunen U, Seppalainen AM, Naukkarinen M. 1979. Changes in the electroretinogram and visual evoked potentials during general anesthesia. 
Albrecht Von Graefes Arch Klein Exp Ophthalmol 211: 139-144.

Rigdon GC, Dyer RS. 1988. Ketamine alters rat flash evoked potentials. Pharmacol Biochem Behav 30: 421-426.

Rosolen SJ, Rigaudiere F, Saint-Macary G, Lachapelle P. 1999. Recording the photopic electroretinogram from conscious adult Yucatan micropigs. Doc Ophthalmol 98: 197-205.

Sannita WG, Balestra V, DiBon G, Marotta V, Rosadini G. 1993. Human flash-VEP and quantitative EEG are independently affected by acute scopolamine. Electroencephal Clin Neurophysiol 86: 275-282.

Sannita WG, Fioretto M, Maggi L, and Rosadini, G. 1988. Effects of scopolamine parenteral administration on the electroretinogram, visual evoked potentials, and quantitative electroencephalogram of healthy volunteers. Doc Ophtalmol 67: 379-388.

Sato S, Sugimoto S, Chiba S. 1982. A procedure for recording electroretinogram and visual evoked potential in conscious dogs. J Pharmacol Meth 8: 173-181.

Schaeppi U, Krinke G, Fink X, Hofer R, Duennenberger D. 1988. Electroretinography in rats. Agents Actions 24, 3-4: 395-402.

Shaw NA. 1998. The relationship between the putative optic pathway potential and the electro- retinogram. Physiol Behav 63: 615-620.

Tallon-Baudry C. 2003. Oscillatory synchrony and human visual cognition. J Physiol Paris 97: 355-363.

Szabò-Salfay O, Pàlhalmi J, Szatmàri E, Barabàs P, Szilàgyi N, Juh àsz G. 2001. The electroretinogram and visual evoked potential of freely moving rats. Brain Res Bull 56: 7-14.

Vaegan AA, Arora A, Crewther SG, Millar TJ. 1990. The effect of various anaesthetics on the spatial tuning of two major wave peaks in the transient pattern electroretinogram of the cat: Evidence for pattern and luminance components. Vision Res 30: 1401-1407.

Van Der Linden S, Panzica F, De Curtis M. 1999. Carbachol induces fast oscillations in the medial but not in the lateral entorhinal cortex of the isolated guinea pig brain. $\mathrm{J}$ Neurophysiol 82: 2441-2450.

Yu M, Liang X, Wen F, Wu DZ, Luo T. 1998. Analysis of oscillatory potentials of flash electroretinogram in frequency domain and time domain in retinal vein occlusion. Yan Ke Xue Bao 14: 176-181, 144.

Zemon V, Kaplan E, and Ratliff F. 1986. The role of GABA-mediated intracortical inhibition in the generation of visual evoked potentials. In: Cracco RQ, Bodis-Wollner I, eds, Evoked Potentials. New York, NY, USA: Alan R. Liss; 287-295. 

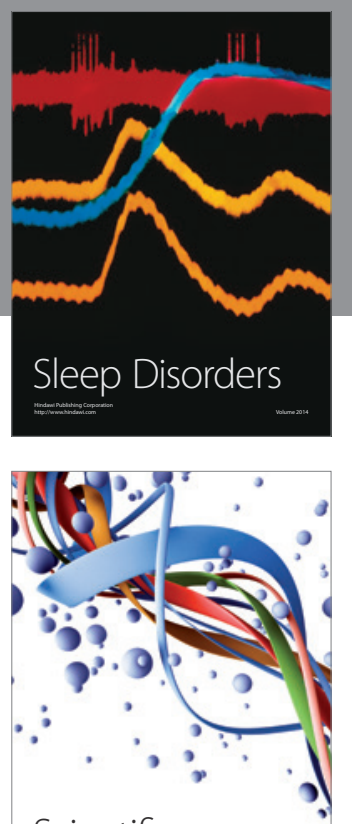

Scientifica
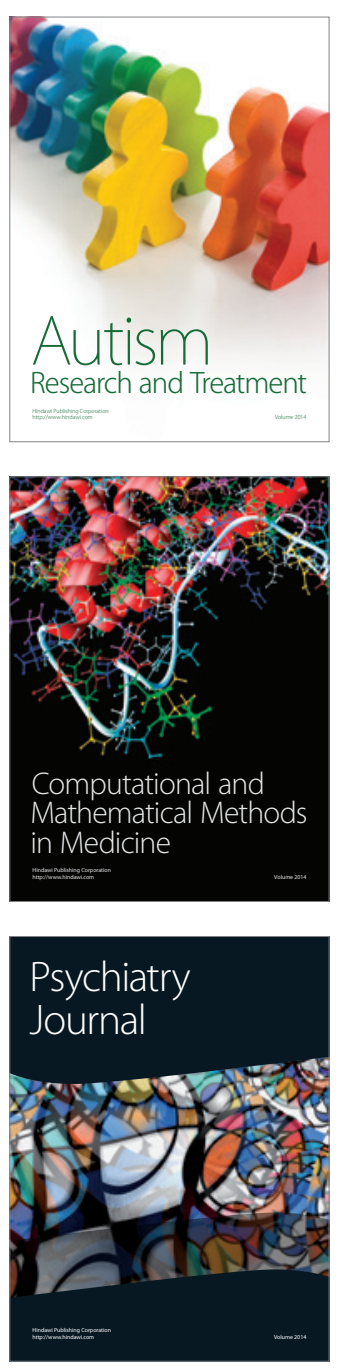
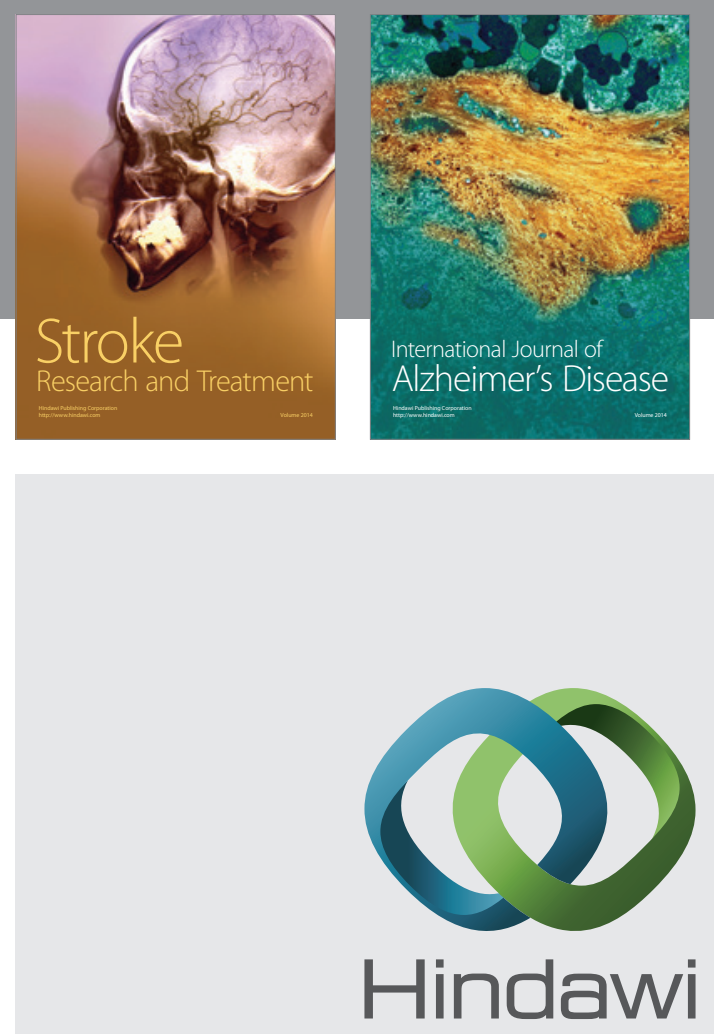

Submit your manuscripts at

http://www.hindawi.com
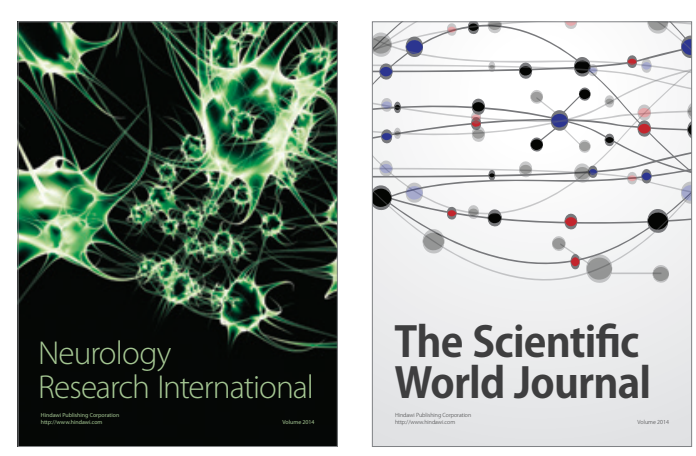

The Scientific World Journal

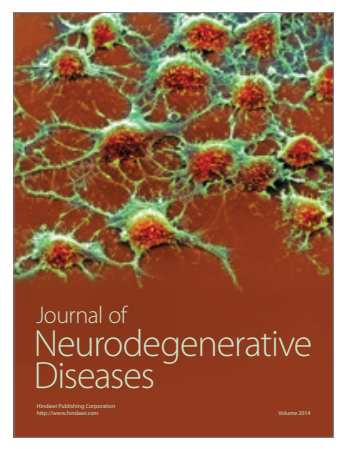

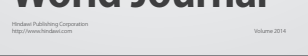

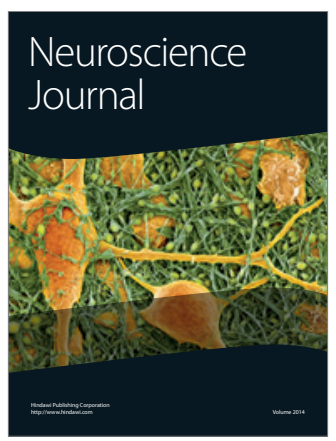

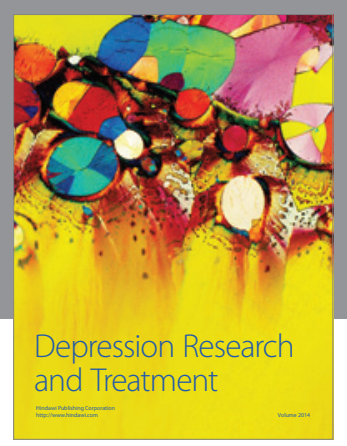
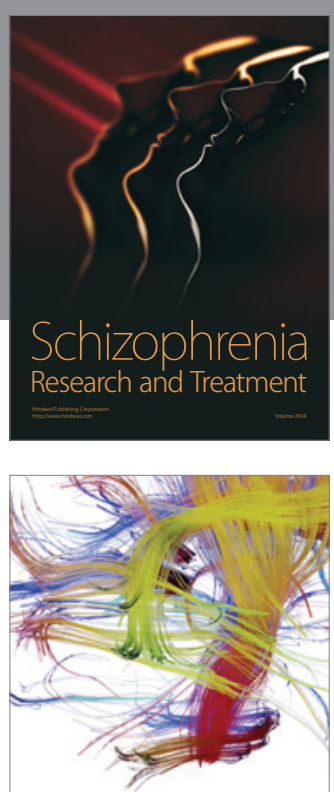

Brain Science

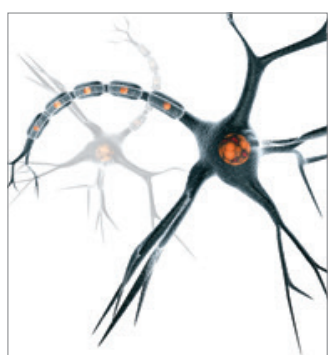

Neural Plasticity
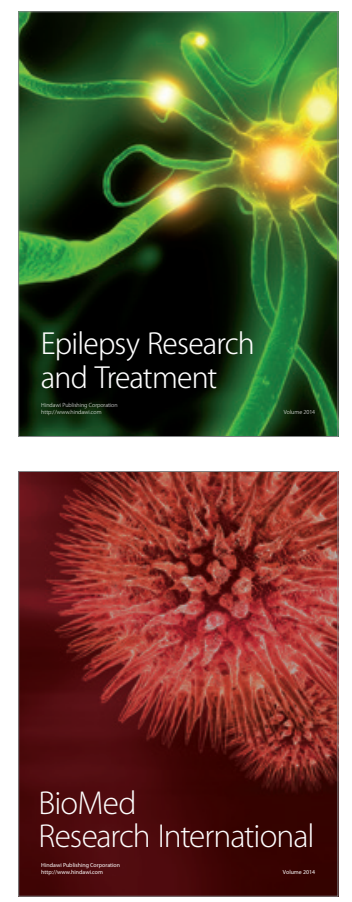

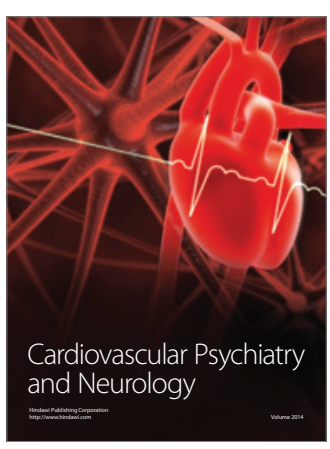

Parkinson's

Disease
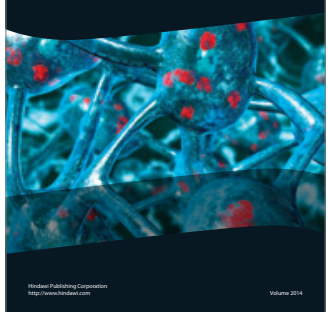